\title{
Mast cell stabilization promotes antinociceptive effects in a mouse model of postoperative pain
}

\author{
This article was published in the following Dove Press journal: \\ Journal of Pain Research \\ I March 2013 \\ Number of times this article has been viewed
}

\section{Makoto Yasuda \\ Kanta Kido \\ Norimasa Ohtani \\ Eiji Masaki}

Department of Dental Anesthesiology and Pain Management, Tohoku University Hospital, Sendai, Japan
Correspondence: Eiji Masaki Department of Dental Anesthesiology and Pain Management, Tohoku University Hospital, 4-I Seiryomachi, Aoba-ku, Sendai $980-8575$, Japan

$\mathrm{Tel}+8 \mathrm{I} 227 \mid 7840$ I

Fax +8I $227 \mid 7840$

Email ejmasaki@m.tohoku.ac.jp
Background: Nerve injury and consequent inflammatory responses produced by surgical incision result in a complicated pain status which still affects half of all surgical patients. Therefore, it is essential for anesthesiologists to identify the mechanisms of postoperative pain. Mast cells are resident cells of connective tissue and the mucosa that participate in the immune response. Degranulation of mast cells is involved in the development of postoperative pain and can be induced by surgical incision. The aim of this study was to investigate whether stabilization of mast cells causes an antinociceptive effect in a mouse model of postoperative pain.

Methods: Postoperative pain was induced by making an incision in the hind paw of BALB/c mice. The mast cell membrane stabilizer cromoglycate $(200 \mu \mathrm{g} / 20 \mu \mathrm{L})$ was injected before incision of the paw, and postoperative pain responses were measured by assessing guarding behavior, withdrawal threshold to mechanical stimuli, and latency of heat pain behavior 1, 2, and 7 days after the incision.

Results: The incision produced guarding pain, mechanical allodynia, and heat hypersensitivity. Cromoglycate decreased the guarding pain score (day 1) and the withdrawal threshold to mechanical stimuli (days 1, 2, and 7). However, the withdrawal latency to heat was not affected by cromoglycate treatment.

Conclusion: Cromoglycate significantly attenuated the pain response expressed as guarding pain and mechanical allodynia in a mouse model of postoperative pain. Thus, mast cell activation is likely a mechanism of postoperative pain and is an interesting target for the development of new therapies.

Keywords: postoperative pain, mast cells, cromoglycate

\section{Introduction}

Postoperative pain, which has both inflammatory and neuropathic components, is difficult to treat, despite effective postoperative analgesia, which improves patient satisfaction and decreases morbidity and mortality after surgery. ${ }^{1}$ Numerous techniques have been advocated, ${ }^{2,3}$ and conventional drugs such as nonsteroidal anti-inflammatory drugs, opioids, and peripheral local anesthetics have been used to control postoperative pain. However, postoperative pain does not always respond to these drugs which are of limited use and may induce side effects. ${ }^{2}$

In peripheral tissue, inflammatory processes after surgical incision are maintained through the release of inflammatory mediators by resident cells, including mast cells. ${ }^{4,5}$ Of the inflammatory mediators released by mast cells, histamine and serotonin have been demonstrated to produce nociception during the postoperative period. In particular, histamine $\mathrm{H}_{3}$ antagonists have shown efficacy in a surgery-induced rat model 
of neuropathic pain. ${ }^{6}$ Preventing degranulation of mast cells was shown to suppress mechanical allodynia and spontaneous pain in a mouse model of postoperative pain, ${ }^{7,8}$ although the studies of mast cell stabilization against nociceptive responses are limited and published from the same group..$^{7-9}$

The aim of this study was to investigate whether mast cell stabilization is effective for attenuating three kinds of elements of postoperative pain as well as confirming the results of previous studies. Therefore, we examined the effect of intraplanter a (ipl) administration of cromoglycate, a mast cell stabilizer, on guarding pain, mechanical allodynia, and heat hypersensitivity in a mouse model of postoperative pain.

\section{Materials and methods General}

All experiments were performed with the approval of the Ethics Committee of Tohoku University School of Medicine and were carried out in accordance with the guidelines for Animal Experiments issued by the Tohoku University School of Medicine. BALB/c adult male mice $(n=20$; body weight, 20-30 g) were used for experiments. Mice had free access to food and water and were maintained under a 12-hour light/ dark cycle before and after surgery.

\section{Drugs}

Sodium cromoglycate was obtained from Sigma-Aldrich (St Louis, MO, USA), diluted in saline, and administered by ipl injection to the mice.

\section{Postoperative pain model}

The postoperative pain model was created by making an incision similar to that described in an earlier study. ${ }^{10}$ Briefly, mice were anesthetized with 3\%-4\% sevoflurane delivered via a nose cone. The left hind paw was sterilized with $10 \%$ povidone-iodine, and an $8 \mathrm{~mm}$ longitudinal incision was made through the skin, fascia, and plantar flexor digitorum brevis muscle of the plantar foot using a \#11 blade. The incision was started $2 \mathrm{~mm}$ from the proximal edge of the heel and extended toward the toes. The skin was closed with two single sutures of 8-0 nylon, and the wound site was covered with antibiotic ointment. Ipl administration of sodium cromoglycate $(200 \mu \mathrm{g} / 20 \mu \mathrm{L})$ was performed in eight mice 20 minutes before the incision procedure (cromoglycate pretreatment group). Eight other mice were given an ipl injection of $20 \mu \mathrm{L}$ saline (saline pretreatment group). Four sham-operated mice, without incision, were used as controls (control group). After surgery, anesthesia was discontinued and the animals were allowed to recover in their cages. On postoperative day 2, sutures were removed under brief anesthesia. Pain behavior was assessed at 1, 2, and 7 days after the incision.

\section{Pain behavioral testing}

The time course for changes in pain behavior after the incision was observed in the following three groups of mice: control, saline pretreatment, and cromoglycate pretreatment groups.

The person investigating the behavioral test was blinded to the group allocation of mice being observed.

\section{Guarding behavior}

For guarding behavior tests, mice were placed individually in clear plastic boxes $(9 \times 9 \times 7 \mathrm{~cm})$ on an elevated stainless steel mesh floor $(4 \times 4 \mathrm{~mm})$. Both the incised and unincised paws of each animal were observed closely for 1 -minute periods every 5 minutes for 1 hour. A score of 0,1 , or 2 was given according to the postural position of each paw as observed in most of the 1-minute scoring periods. If the wound area was blanched or distorted by the mesh, 0 was given. If the paw was completely off the mesh, 2 was given. If the wound area touched the mesh without blanching or distorting, 1 was given. The sum of the 12 scores (0-24) obtained during the 1-hour session for each paw was obtained. The guarding score was then obtained by subtracting the score of the incised hind paw from that of the nonincised hind paw.

\section{Response to mechanical stimuli}

For mechanical withdrawal threshold testing, the mice were placed on an elevated stainless steel floor covered with a clear plastic box top. Calibrated von Frey filaments were applied adjacent to the wound from least to greatest force $(0.7,2.0,3.1,5.9,14.0$, and $26.4 \mathrm{mN})$. Each filament was applied five times, with 30 seconds between applications. Data are expressed as the percent of paw withdrawals for each filament.

\section{Response to heat}

For heat withdrawal latency testing, the mice were placed individually on a glass floor. The heat stimulus was light from a $50 \mathrm{~W}$ projector lamp with an aperture diameter of $6 \mathrm{~mm}$ applied to the middle of the incision from beneath the glass floor. The latency time to evoke a withdrawal was determined with a cutoff value of 30 seconds. The intensity of the heat was adjusted to produce withdrawal latency of 25-30 seconds in normal mice. Three trials were conducted 5-10 minutes apart to obtain average paw withdrawal latency. 


\section{Statistical analysis}

Normal distribution of values was determined by the D'Agostino-Pearson test. All data were analyzed using a repeated-measures two-way analysis of variance (ANOVA) with a post hoc $t$-test with Bonferroni correction to determine differences between the groups. A $P$-value less than 0.05 was considered significant. Data are expressed as mean \pm standard deviation values and were analyzed in GraphPad Prism 6 software (GraphPad Software, Inc, La Jolla, CA, USA).

\section{Results}

\section{Guarding behavior}

The guarding pain score increased after plantar incision in both the saline pretreatment and cromoglycate pretreatment groups (Figure 1). Pretreatment with cromoglycate significantly reduced the guarding pain score on postoperative day 1 compared to saline $(P<0.05)$. The mean guarding pain score in the saline pretreatment and cromoglycate pretreatment groups was $16.4 \pm 2.2$ and $6.0 \pm 1.4$, respectively. Guarding pain resolved 7 days after surgery.

\section{Response to mechanical stimuli}

The presence of an incision increased the frequency of withdrawal responses to all six von Frey filaments. Cromoglycate pretreatment was not effective in the response to the weakest $(0.7 \mathrm{mN}$; Figure $2 \mathrm{~A})$ and strongest $(26.4 \mathrm{mN}$; Figure $2 \mathrm{~F})$ force. At the moderate force levels $(2-14 \mathrm{mN}$; Figure 2B-E), cromoglycate reduced the responses to mechanical stimuli after plantar incision, especially at 2 days after surgery. In addition, cromoglycate pretreatment mice were likely to recover from postoperative hyperalgesia faster than saline pretreatment mice.

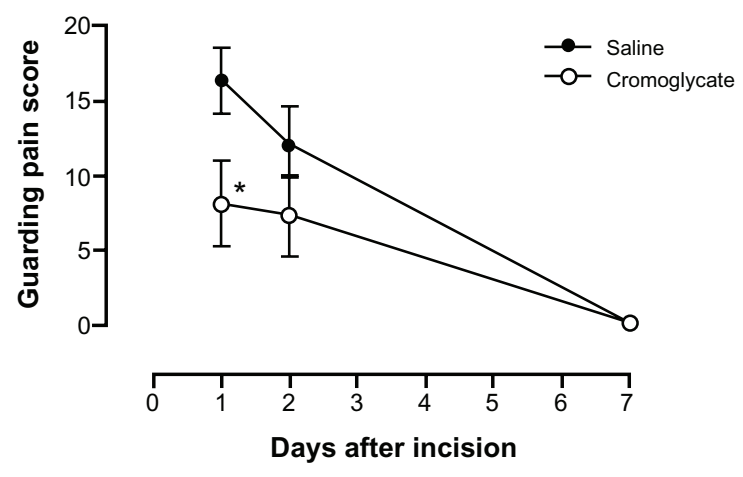

Figure I Effect of cromoglycate on guarding pain I, 2, and 7 days after incision. Notes: The data were analyzed using a repeated-measures two-way ANOVA with a post hoc $t$-test with Bonferroni correction to determine differences between the saline group $(n=8, \bullet)$ and the cromoglycate group $(n=8, \circ)$. The score of the control group is 0 (not shown). Scores are expressed as mean \pm SD values. $* P<0.05$. Abbreviations: ANOVA, analysis of variance; SD, standard deviation.

\section{Response to heat stimuli}

The presence of an incision induced a lower withdrawal latency than that of the sham control. There was no difference between the pretreatment with saline and cromoglycate groups from day 1 to day 7 after surgery (Figure 3). Both mouse groups recovered from postoperative heat sensitivity 7 days after surgery. Cromoglycate was not effective in the response to heat stimuli in the postoperative pain model.

\section{Discussion}

Analysis of pain responses revealed that an ipl injection of cromoglycate before the incision induced an antinociceptive effect. Ipl administration of cromoglycate resulted in the following important changes: (1) a reduction in surgeryinduced spontaneous pain as expressed by decreased guarding pain scores; (2) an increase in the withdrawal threshold to mechanical stimulation; and (3) no effect on withdrawal latency to heat stimulation. These findings suggest that stabilization of mast cells at an operation site may be a novel means for managing perioperative pain. However, further studies are necessary for clinical use to assess potential adverse effects and to develop new techniques, including effective administration routes for stabilizing mast cells.

Surgical incision and peripheral nerve injury produce numerous modulators, such as neurotrophic factors, cytokines, and biogenic amines. ${ }^{11}$ Such modulators can cause an inflammatory response which alters the excitability of sensory neurons, resulting in complicated pain responses ${ }^{12,13}$ that are difficult to treat with conventional analgesics such as opioids and non-steroidal anti-inflammatory drugs. However, these pain responses may respond to other classes of analgesics such as $\alpha_{2}$-receptor agonists, ${ }^{14}$ anticonvulsants, ${ }^{15}$ and antidepressants. ${ }^{16}$ Ipl administration of cromoglycate stabilizes mast cells and inhibits the release of biogenic amines including histamine and serotonin, resulting in an antinociceptive effect. The analgesic mechanisms of $\alpha_{2}$-receptor agonists, anticonvulsants, and antidepressants are different, and cromoglycate has the potential to become another class of analgesics to control postoperative pain at the incision site.

In the present study, three kinds of pain responses were assessed, and cromoglycate had a different effect on each response. Guarding pain and mechanical allodynia, but not heat hypersensitivity, were sensitive to cromoglycate. Furthermore, the duration of cromoglycate's effectiveness was short for guarding pain but long for mechanical allodynia. It has been suggested that the signal of each of the three kinds of pain response differs between the primary afferent and 
A

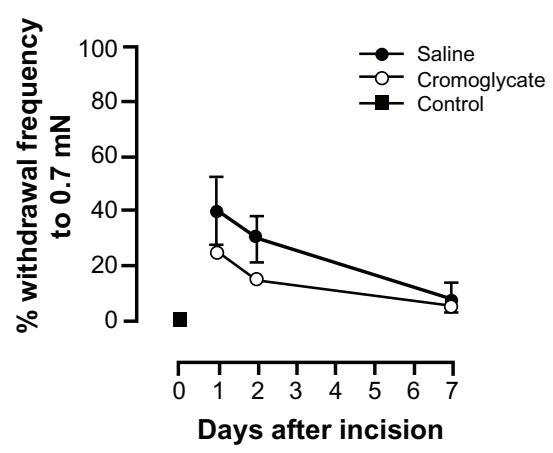

C

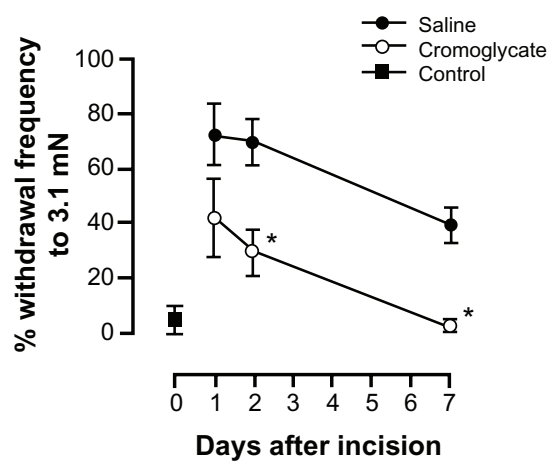

E

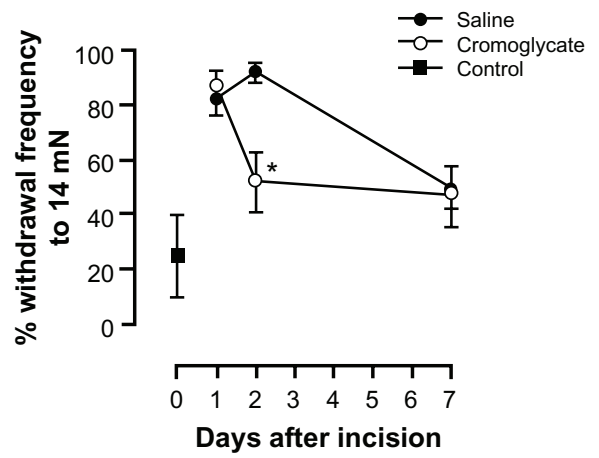

B

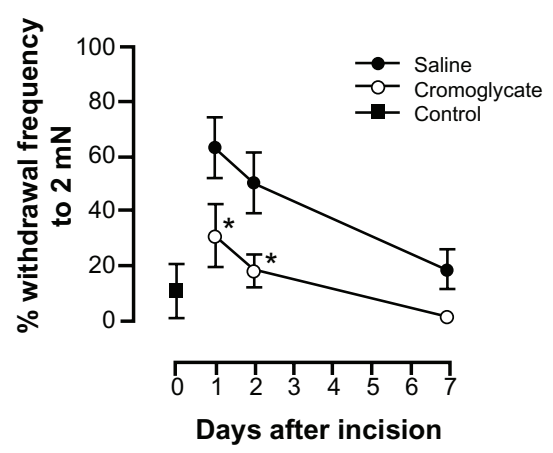

D

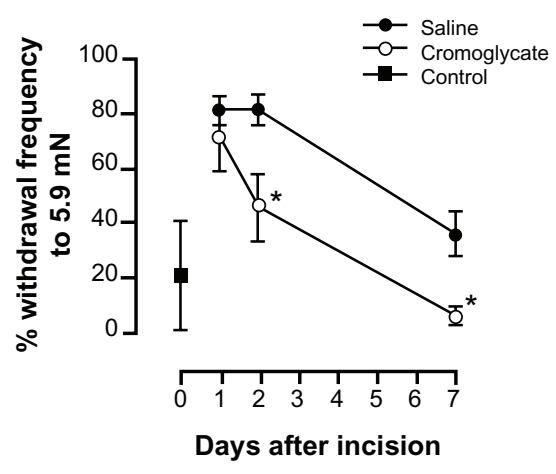

F

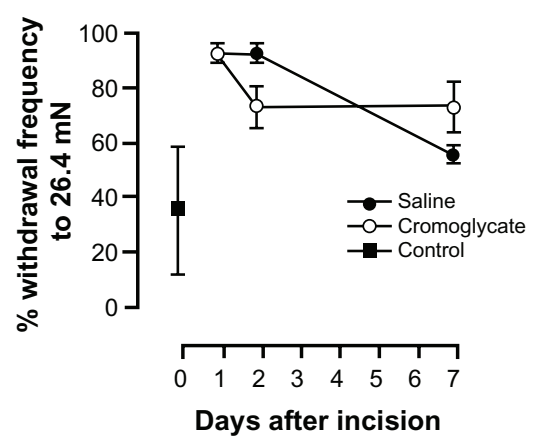

Figure 2 Effect of cromoglycate on mechanical allodynia I, 2, and 7 days after incision. The data were analyzed using a repeated-measures two-way ANOVA with a post hoc $t$-test with Bonferroni correction to determine differences between the saline group $(n=8, \bullet)$ and the cromoglycate group $(n=8, \circ)$. Black squares indicate the control group $(n=4)$. Response frequency scores are expressed as mean $\pm \mathrm{SD}$ values. (A) $0.7 \mathrm{mN}$; (B) $2 \mathrm{mN}$; (C) $3.1 \mathrm{mN}$; (D) $5.9 \mathrm{mN}$; (E) I4 mN; (F) $26.4 \mathrm{mN}$. $* p<0.05$.

Abbreviations: ANOVA, analysis of variance; SD, standard deviation.

dorsal horn neurons. In the peripheral nerve, A- $\delta$ and C-fibers are sensitized to mechanical stimuli from an incision; ${ }^{17}$ however, no reports have demonstrated heat sensitivity in afferent innervation following an incision. On the other hand, a separate group of dorsal horn neurons have been shown to transmit spontaneous pain activity and mechanical allodynia one day after plantar incision. ${ }^{18}$ After surgical incision and mast cell degranulation, released histamine and serotonin bind to their receptors on primary afferents to produce nociception. ${ }^{19,20}$ Receptor density and/or receptor potential might differ between afferents connecting to separate groups of dorsal horn neurons. Therefore, stabilization of mast cells at the surgical site by cromoglycate will produce a different effect for each kind of pain response.

There are several limitations to this study. First, we examined the effect of only a single dose of ipl administration of cromoglycate. Therefore, if a larger dose of cromoglycate than that used in the present study is injected, a superior and longer-lasting effect on guarding pain and heat hypersensitivity may be achieved. The dose of cromoglycate in the present study was determined on the basis of doses used in previous studies. ${ }^{7}$ The study using 


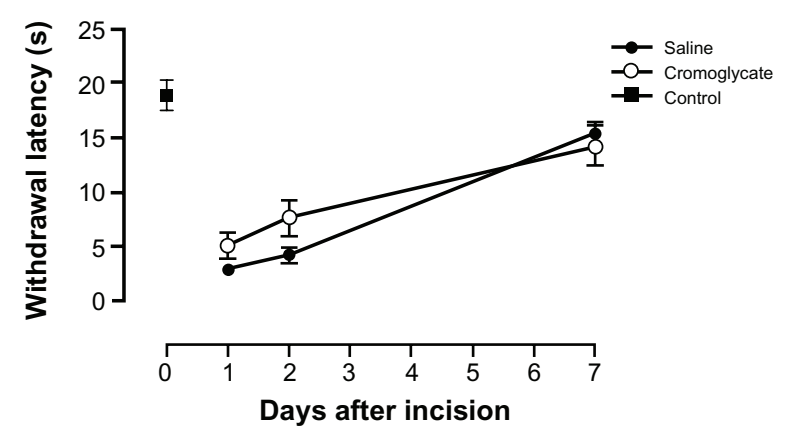

Figure 3 Effect of cromoglycate on heat withdrawal latency I, 2, and 7 days after incision.

Notes: The data were analyzed using a repeated-measures two-way ANOVA with a post hoc $t$-test with Bonferroni correction to determine differences between the saline group $(n=8, \bullet)$ and the cromoglycate group $(n=8, \circ)$. Black square indicates the control group $(n=4)$. Heat withdrawal latency scores are expressed as mean \pm SD values.

Abbreviations: ANOVA, analysis of variance; SD, standard deviation.

larger doses of cromoglycate is under investigation, however, a much smaller dose of cromoglycate showed antinociceptive effects on monosodium urate induced pain in rats. ${ }^{9}$ The dose responses on each pain behavior are needed to better identify the role of cromoglycate. Second, in this study, the direct evidence for stabilization of mast cells and for involvement of histamine and serotonin in incision pain, such as reduced degranulation of mast cells, decreased release of histamine and serotonin, and antagonisms of incision pain by histamine and serotonin antagonists, were not identified. Therefore, it is possible that the behavioral changes observed are due to other effects of cromoglycate. Neverthless the stabilization of cromoglycate and the antagonisms of incision pain were ascertained in postoperative pain ${ }^{7-9}$ along with other kinds of pain models. ${ }^{21-23}$ We could have examined the effects of histamine and serotonin antagonists, however, not only histamine and serotonin but other kinds of mediators are released after activation of mast cells by surgical incision. Recently, Oliveira et al have demonstrated that mast cells activated by surgical incision released tryptase which stimulates protease-activated receptor 2 , resulting in spontaneous pain and hypersensitivity. ${ }^{8}$ Antagonism of protease-activated receptor 2 as well as stabilization of mast cells reduced both spontaneous pain and hypersensitivity. Those results are consistent with ours in terms of effects of mast cell stabilizer. Third, ipl administration of cromoglycate might not be suitable for future clinical settings. In addition, the model used in this study was not appropriate for testing analgesic effects of cromoglycate because it could assess aspects of peripheral nerve dysfunction but not the emotional aspects that humans report are the most distressing aspect of the feeling. In the present study, it is probable that stabilization of mast cells before surgical incision may be useful for controlling postoperative pain, suggesting cromoglycate could become one of the candidates to control postoperative pain. However, in a clinical setting, it is inappropriate to administer cromoglycate to all incision sites. Stabilization of mast cells at surgical sites requires development of an improved approach, such as a neuraxial or parenteral route.

\section{Conclusion}

Mast cell activation is an important peripheral mechanism mediating the development and maintenance of postoperative pain. In addition, stabilization of mast cells may form the basis for interesting new developments to treat postoperative pain. However, further studies in a clinical setting are necessary for assessing potential adverse effects and to develop new techniques, including effective administration routes for stabilizing mast cells.

\section{Acknowledgments}

This study was supported in part by a Grant-in-Aid for Scientific Research from the Ministry of Education, Culture, Sports, Science and Technology of Japan to MY (No 24792167), KK (No 24593047), NO (No 2493046), and EM (No 22659362).

\section{Disclosure}

The authors report no conflicts of interest in this work.

\section{References}

1. Kehlet H, Jehsesn TS, Woolf CJ. Persistent postsurgical pain: risk factors and prevention. Lancet. 2006;367(9522):1618-1625.

2. Dahl JB, Kehlet H. Postoperative pain and its management. In: McMahon SB, Klotzenburg M, editors. Textbook of Pain. Philadelphia: Elsevier Science Health Science Division; 2006:635-651.

3. Møiniche S, Kehlet H, Dshj JB. A qualitative and quantitative systematic review of preemptive analgesia of postoperative pain relief: the role of timing of analgesia. Anesthesiology. 2002;96(3):725-741.

4. Basbaum AI, Bautista DM, Scherrer G, Julius D. Cellular and molecular mechanisms of pain. Cell. 2009;139(2):267-284.

5. Marchand F, Perretti M, McMahon SB. Role of the immune system in chronic pain. Nat Rev Neurosci. 2005;6(7):521-532.

6. Medhurst SJ, Collins SD, Billinton A, et al. Novel histamine H3 receptor antagonists GSK189254 and GSK334429 are efficacious in surgically-induced and virally-induced rat model of neuropathic pain. Pain. 2008;138(1):61-69.

7. Oliveira SM, Drewes CC, Silva CR, et al. Involvement of mast cells in a mouse model of postoperative pain. Eur J Pharmacol. 2011;672(1-3): 88-95.

8. Oliveira SM, Silva CR, Ferreira J. Critical role of protease-activated receptor 2 activation by mast cell tryptase in the development. Anesthesiology. Epub December 17, 2012.

9. Hoffmeister C, Trevisan G, Rossato MF, de Oliveira SM, Gomez MV, Ferreira J. Role of TRPV1 in nociception and edema induced by monosodium urate crystals in rats. Pain. 2011;152(8):1777-1788. 
10. Pogatzki EM, Raja SN. A mouse model of incision pain. Anesthesiology. 2003;99(4):1023-1027.

11. Hefti FF, Rosenthal A, Waliche PA, et al. Novel class of pain drug based on antagonism of NGF. Trends Pharmacol Sci. 2006;27(2):85-91.

12. Coderre TJ. The role of excitatory amino acid receptors and intracellular messengers in persistent nociception after tissue injury in rats. Mol Neurobiol. 1993;7(3-4):229-246.

13. MacFarlane BV, Wright A, O'Callaghan J, Benson HA. Chronic neuropathic pain and its control by drugs. Pharmacol Ther. 1997;75(1): $1-19$.

14. Xu XJ, Puke MJ, Wiesenfeld-Hallin Z. The depressive effect of intrathecal clonidine on the spinal flexor reflex is enhanced after sciatic nerve section in rats. Pain. 1992;51(2):145-151.

15. Gottrup H, Juhl G, Kristensen AD, et al. Choronic oral gabapentin reduces elements of central sensitization in human experimental hyperalgesia. Anesthesiology. 2004;101(6):1400-1408.

16. Abdi S, Lee DH, Chung JM. The anti-allodynic effects of amitriptyline, gabapentin, and lidocaine in a rat model of neuropathic pain. Anesth Analg. 1998;87(6):1360-1366.

17. Banik RK, Brennan TJ. Spontaneous discharge and increased heat sensitivity of rat $\mathrm{C}$-fiber nociception are present in vitro after plantar incision. Pain. 2004;112(1-2):204-213.
18. Xu J, Richebe P, Brennan TJ. Separate groups of dorsal horn neurons transmit spontaneous activity and mechanosensitivity one day after plantar incision. Eur J Pain. 2009;13(8):820-828.

19. Ren K, Dubner R. Interaction between the immune and nervous system in pain. Nat Med. 2010;16(11):1267-1276.

20. Wei H, Chen Y, Hong Y. The contribution of peripheral 5-hydroxytryptamine2A receptor to carrageenan-evoked hyperalgesia, inflammation and spinal Fos protein expression in the rat. Neuroscience. 2005;132(4):1073-1082.

21. Ting E, Roveroni RC, Ferrari LF, et al. Indirect mechanism of histamineinduced nociception in temporomandibular joint of rats. Life Sci. 2007;81(9):765-771.

22. Godínez-Chaparro B, Barragán-Iglesias P, Castañeda-Corral G, Rocha-González HI, Granados-Soto V. Role of peripheral 5-HT(4), 5-HT(6), and 5-HT(7) receptors in development and maintenance of secondary mechanical allodynia and hyperalgesia. Pain. 2011;152(3): 687-697.

23. Nakajima K, Obata H, Ito N, Goto F, Saito S. The nociceptive mechanism of 5-hydroxytryptamine released into the peripheral tissue in acute inflammatory pain in rats. Eur J Pain. 2009;13(5):441-447.
Journal of Pain Research

\section{Publish your work in this journal}

The Journal of Pain Research is an international, peer-reviewed, open access, online journal that welcomes laboratory and clinical findings in the fields of pain research and the prevention and management of pain. Original research, reviews, symposium reports, hypothesis formation and commentaries are all considered for publication.

\section{Dovepress}

The manuscript management system is completely online and includes a very quick and fair peer-review system, which is all easy to use. Visit http://www.dovepress.com/testimonials.php to read real quotes from published authors. 